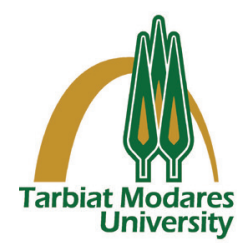

\title{
Incidence of Dominant Metallo- $\beta$-Lactamase Resistance Genes Produced in Pseudomonas aeruginosa Burn Infections in Iran: A Systemic Review and Meta-Analysis
}

\section{A R T I C L E I N F O}

Article Type

Review Article

Authors

Leila Shamkhali, $M S c^{1}$

Mahla Shahriari, $M S c^{2}$

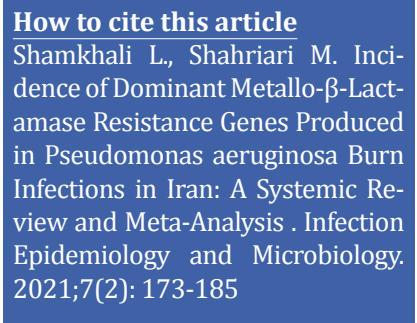

${ }^{1} \mathrm{PhD}$ student, Tarbiat Modares University, Tehran, Iran ${ }^{2} \mathrm{PhD}$ student,Tarbiat Modares University, Tehran, Iran

\section{* Correspondence \\ Address: Nasr, Jalal AleAhmad,Tehran. P.O.Box: $14115-111$ Tel: +989126025801 Leila.shamkhali@modares.ac.ir}

\section{A B S T R A C T}

Backgrounds: Metallo- $\beta$-Lactamase (MBL) enzymes-producing Pseudomonas aeruginosa strains are one of the most important causes of nosocomial infections and are very difficult to treat, leading to high mortality rate. Therefore, control of these cases is very important, especially in burns. This study aimed to systematically review published data on MBL genes prevalence among $P$. aeruginosa strains isolated from burn patients.

Materials \& Methods: ISI Web of Science, Scopus, PubMed, and Google Scholar were searched using appropriate key terms as follows: $P$. aeruginosa, metallo- $\beta$-lactamase, burn patients, imipenem resistant, and Iran. Antibiotic susceptibility tests were conducted by Kirby-Bauer disc diffusion and broth microdilution methods according to the CLSI guidelines. The MBL producers was evaluated by the combination disk diffusion test (CDDT), and detection of genes such as bla ${ }_{I M P}, b l a_{V I M}, b l a_{S P M}$ and $b l a_{N D M}$ was performed with polymerase chain reaction (PCR). In this review statistical analyses were performed using STATA statistical software Ver.13.

Results: Out of 410 retrieved articles, 18 articles were eligible to be included in this systematic review and meta-analysis. These studies were carried out in Tehran, Shiraz, Yazd, Zahedan, and other locations. Pooled estimation of all $P$. aeruginosa strains included in 18 studies showed that the prevalence of MBL-producing $P$. aeruginosa strains in Iranian population was about 49\% (95\% CI: 33-65). The present study findings also revealed that in Iranian population, the most prevalent MBL genes were $b l a_{I M P}$ with $17 \%$ (95\% CI) and bla with $13 \%$ (95\% CI), respectively.

Conclusion: Detection of these bacterial resistance genes should be performed nationally, and strict control measures should be put on the agenda to reduce the incidence of these cases.

Keywords: Pseudomonas aeruginosa, Imipenem resistant, Metallo- $\beta$-lactamase, Burn patients, Iran

\section{CITATION LINKS}

[1] Jabalameli F, Taki E, Emaneini M, ... [2] Faghri J, Nouri S, Jalalifar S, Zalipoor ... [3] Morita Y, Tomida J, Kawamura Y. Responses of ... [4] Rostami S, Farajzadeh Sheikh A, ... [5] El-Domany RA, Emara M, El-Magd MA, Moustafa ... [6] Khosravi AD, Shafie F, Abbasi Montazeri E, Rostami ... [7] Khosravi AD, Mihani F. Detection of metallo- $\beta$-lactamase-producing ... [8] Malkoçoğlu G, Aktaş E, Bayraktar B, Otlu B, Bulut ME. VIM-1, VIM-2, and ... [9] Jeon JH, Lee JH, Lee JJ, Park KS, Karim AM, Lee CR, et al. Structural. ... [10] Hong DJ, Bae IK, Jang IH, Jeong SH, Kang HK, Lee K. Epidemiology. ... [11] Ramakrishnan K, Rajagopalan S, Nair S, Kenchappa P, Chandrakesan. ... [12] Diene SM, Rolain JM. Carbapenemase genes and ... [13] Soares De Macedo JL, Santos JB. Bacterial and ... [14] Kalantar E, Torabi V, Salimizan, ... [15] Franklin C, Liolios L, Peleg AY. Phenotypic ... [16] Gupta V, Datta P, Chander J. Prevalence of ... [17] El-Mokhtar MA, Hassanein KM, Ahmed AS, Gad GFM, Amin ... [18] Moghadam SS, Khodaii Z, Zadeh SF, Ghooshchian M, Aghmiyuni ... [19] Vaez H, Khademi F, Salehi-Abargouei A, Sahebkar ... [20] Lautenbach E, Synnestvedt M, Weiner MG, Bilker ... [21] Erlandsson M, Gill H, Nordlinder D, Giske C, Jonas D, Nilsson LE, et al.... [22] Liakopoulos A, Mavroidi A, Katsifas EA, Theodosiou A, Karagouni AD, ... [23] Yong D, Toleman MA, Giske CG, Cho HS, Sundman K, ... [24] Kaleem F, Usman J, Hassan A, Khan A. Frequency and ... [25] Hashem H, Hanora A, Abdalla S, Shaeky A, Saad A... [26] Ghasemian A, Rizi KS, Vardanjani HR, Nojoomi F.... [27] Samuelsen Ø, Toleman MA, Sundsfjord A, Rydberg J, ... [28] Tafti A, Zandi H, Vakli M, Mousavi SM, Zarei M. Frequency ... [29] Ramos-Vivas J, Chapartegui-González I, Fernández-Martínez ... [30] Rasamiravaka T, Labtani Q Duez P, El Jaziri M. The formation ... [31] Mock C, Peck M, Peden M, Krug E, ... [32] Sadredinamin M, Hashemi A, Goudarzi H, ... [33] Weber J, McManus A, ... [34] Ducel G, Fabry J, Nicolle ... [35] Arslan E, Dalay C, Yavuz M, Göcenler L, Acartürk S. ... [36] Hakemi Vala M, Hallajzadeh M, Hashemi A, Goudarzi H, ... [37] Sadredinamin M, Hashemi A, Goudarzi H, ... [38] Hashemi A, Fallah F, Erfanimanesh S, Chirani A, Dadashi M. ... [39] Radan M, Moniri R, Khorshidi A, Gilasi H, Norouzi Z, Beigi F, et al. ... [40] Saffari M, Firoozeh F, Pourbabaee M, Zibaei M. Evaluation of ... [41] Tarashi S, Goudarzi H, ... [42] Azimi A, Peymani A, ... [43] Emami A, Pirbonyeh N, ... [44] Farajzadeh Sheikh A, Shahin M, ... [45] Asadpour L. Antimicrobial ... [46] Salimi ... [47] Ghamgosha M, Shahrekizahedani S, ... [48] Hemmati F, Sourouri Zanjani R ... [49] Nakhaei Moghaddam M. HMH. ... [50] Rostam Pour S, Gorzin A, Motamedi G. Frequency ... 


\section{Introduction}

A major leading cause of life-threatening infections is Pseudomonas aeruginosa in burn patients worldwide ${ }^{[1]}$. P. aeruginosa is one of most important causes of hospitalacquired infections ${ }^{[2]}$. It is an opportunistic microorganism involved in many infections, such as urinary tract infections, respiratory infections, bacteremia, and wound and soft tissue infections, especially in immunocompromised patients and in patients with dermal injuries ${ }^{[3-4]}$.

Notwithstanding advances in medicine, $P$. aeruginosa is considered a significant infectious threat to patients with burn injuries. $P$. aeruginosa shows a primary resistance to many antimicrobial agents through the outer membrane barriers, multidrug efflux pumps, and endogenous antimicrobial inactivation. Selection of an appropriate antibiotic is predicated based on the capability of $P$. aeruginosa to develop resistance to multiple categories of antibacterial agents, and the selection of a suitable antibiotic to begin treatment is a necessity optimizing the clinical outcome ${ }^{[4]}$. This pathogen has a considerable capacity to develop resistance to multiple categories of antimicrobial agents and as a result, it is considered as a multidrug resistant pathogen ${ }^{[5]}$.

Today, carbapenem-resistant $P$. aeruginosa has increased significantly, causing high mortality rate among patients with nosocomial infections. One of the most important mechanisms of resistance in this pathogen is the ability to produce metallo$\beta$-lactamase (MBL) enzymes ${ }^{[6-8]}$. These enzymes could hydrolyze antibiotics, such as penicillins and cephalosporins ${ }^{[9]}$, and have different types, including São Paulo metalo$\beta$-lactamase (SPM), Germany imipenemase (GIM), Verona integron-encoded metallo$\beta$-lactamase (VIM), Seoul imipenemase (SIM), New Delhi metallo- $\beta$-lactamase, and imipenemase (IMP). VIM and IMP are the most common types of acquired MBLs ${ }^{[10-11]}$. VIM type was first reported in Italy, whereas in early 1991, the IMP-type enzymes initially emerged in Japan. However, both types have been increasingly reported in other parts of the world ${ }^{[12]}$. These genes are encoded by mobile genetic elements (integrons, plasmids, transposons) and transmitted among Gram-negative bacteria [13].

For this reason, they are found in all parts of the world. In Iran, the first case of $P$. aeruginosa metallo- $\beta$-lactamase resistance in burn centers was reported in 2008. After that, from 2008 to 2016, its rate in burn centers increased from 41 to $57 \%$ and caused serious concerns [6-7].

Despite advances in antimicrobial therapies, bacterial infections are one of the major problems among burn patients. About $75 \%$ of deaths in this group of patients is due to refractory infections [13]. Recently, $P$. aeruginosa has been identified as one of the main causes of various nosocomial infections, especially in burn units. The spread of drug resistance is very fast, which in turn could cause many problems in the treatment process ${ }^{[14]}$.

With all these interpretations, there is no standard phenotypic corroborant test for the detection of MBLs among $P$. aeruginosa isolates ${ }^{[15]}$. Molecular procedures are essential to verify the presentment of MBL genes in clinical isolates and are also considered as suitable instruments for detection and screening. PCR (Polymerase chain reaction) test has high sensitivity and reliability for the detection of MBL genes between MBL-producing $P$. aeruginosa isolates [16].

One of the reasons for high resistance of $P$. aeruginosa to antimicrobials is the ability to form strong biofilms because the bacteria in the biofilm are resistant not only to the host immune system but also to antibiotics. For 
this reason, effective treatment strategies should be used to deal with such cases ${ }^{[17]}$. In recent years, the role of probiotics in controlling $P$. aeruginosa infections in burn patients has been investigated and introduced as one of the therapeutic options. For this reason, many studies have examined the role of antibacterial probiotics in inhibiting the growth of resistant pathogens ${ }^{[18]}$.

Objectives: This meta-analysis study aimed to systematically review published data on MBL genes prevalence among $P$. aeruginosa strains isolated from burn patients in different locations of Iran during 2011-2020, with the aim of emphasizing the importance of this issue and providing useful suggestions to solve these problems.

\section{Materials and Methods}

Search strategies: In this study, international databases (ISI Web of Science, Scopus, PubMed, and Google Scholar) as well as two national scientific search engines including Magiran (www.magiran.com) and Iranian Scientific Information database (www.sid.ir) were searched for articles published from 2011 to 2020 without limitation using the following terms: Pseudomonas aeruginosa or P. aeruginosa, metallo- $\beta$-lactamases or MBLs, and burn patients in combination with Iran and "multidrug-resistant P. aeruginosa". Those articles reporting the prevalence of MBLs in burn patients were considered. Cross-sectional or cohort studies reporting the prevalence of MBLs in burn patients were considered. Review studies revealing the prevalence or incidence of MBLs genes in burn patients were restricted to studies published in English and Persian languages. Studies with the following characteristics were included: studies conducted only on burn patients and reporting the frequency of carbapenem resistance and MBLs genes. Studies that had one or more of the following characteristics were excluded: studies using phenotypic methods, duplicate and overlapping studies, studies published in languages other than English or Persian, studies performed on patients other than burn patients, studies that did not report CRPA and MBLs prevalence, nonhuman studies, review articles, congress abstracts, meta-analyses, systematic reviews, as well as articles available only in abstract form. References list of all studies was also reviewed for any other related publication. Some references were also entered manually. Inclusion criteria: Inclusion criteria used in the present study were as follows:

- P.aeruginosa isolates collected from patients referring to Iranian hospitals.

- P. aeruginosa strains collected from clinical samples.

- P. aeruginosa strains collected from burn patients.

Phenotypic methods (imipenem/meropene) alone and in combination with EDTA were used according to CLSI guidelines to detect the prevalence of MBL producing isolates of $P$. aeruginosa because these are approved methods that are widely available.

Exclusion criteria: Studies with unclear materials, methods, and the origin of samples were excluded.

Statistical analysis: Statistical analyses were performed using STATA statistical software Ver.13 (Stata Corp. 2013. Stata Statistical Software: Release 13. College Station, TX: Stata Corp LP). Heterogeneity assessment between studies was performed using the $\mathrm{I}^{2}$ statistic (the $\mathrm{I}^{2}$ values of 25,50 , and $75 \%$ indicated low, moderate, and high heterogeneities, respectively) which represents the percentage of total variation that is true between-studies heterogeneity. A random-effects model was used if heterogeneity was high $\left(\mathrm{I}^{2}>50 \%\right)$; otherwise, a fixed effects model was applied. Double arcsine transformations were applied to stabilize the variance in the meta-analyses, Significance level was set at $p<.05$. Then the 
Table 1) Prevalence of MBL genes based on different locations.

\begin{tabular}{|c|c|c|c|c|c|c|c|}
\hline & \multirow{2}{*}{ First Author } & \multirow{2}{*}{ Location (Ref.) } & \multirow{2}{*}{$\begin{array}{l}\text { Time of } \\
\text { Study }\end{array}$} & \multirow{2}{*}{$\begin{array}{c}\text { Total } \\
\text { Samples }\end{array}$} & \multirow{2}{*}{$\begin{array}{c}\text { MBL } \\
\text { Proportion } \\
(\%)\end{array}$} & \multicolumn{2}{|c|}{$\begin{array}{c}\text { MBL-Genes } \\
\text { (Proportion \%) }\end{array}$} \\
\hline & & & & & & VIM & IMP \\
\hline 1 & Hakemi Vala & Tehran(36) & $2013-2014$ & 47 & 17.8 & 0.1 & 2.1 \\
\hline 2 & Sadredinamin & Tehran(37) & $2014-2015$ & 100 & 81 & 0 & 16 \\
\hline 3 & Hashemi. & Tehran(38) & 2012 & 100 & 62.33 & 0 & 7.7 \\
\hline 4 & Radan & Esfahan(39) & $2013-2014$ & 150 & 96 & NA & 74.3 \\
\hline 5 & Saffari & Esfahan(40) & $2014-2015$ & 150 & 96 & 23.5 & NA \\
\hline 6 & Tarashi & Tehran(41) & $2012-2015$ & 309 & 64.02 & 29.2 & 16.8 \\
\hline 7 & Rostami. & $\begin{array}{l}\text { Ahvaz(4)blaVIM, blaSPM } \\
\text { and blaNDM }\end{array}$ & 2011-2012 & 107 & 14.9 & 1.2 & 17.9 \\
\hline 8 & Azimi & Tehran(42) & $2015-2016$ & 160 & 43.7 & 17.5 & 15.6 \\
\hline 9 & Emami & Shiraz(43) & $2017-2018$ & 48 & 33.33 & 61.6 & 0 \\
\hline 10 & Farajzadeh Sheikh & $\operatorname{Iran}(44)$ & $2013-2016$ & 369 & 31.43 & 28.8 & 21.6 \\
\hline 11 & Kalantar & Kurdistan(14) & $2011-2012$ & 145 & 22 & NA & NA \\
\hline 12 & Asadpour & Northen iran(45) & 2018 & 90 & 35.6 & NA & NA \\
\hline 13 & Salimi & Tehran(46) & 2014 & 32 & 100 & 46.8 & 56.2 \\
\hline 14 & Ghamgosha & Zahedan(47) & $2012-013$ & 191 & 4.7 & 3.7 & 0.3 \\
\hline 15 & Hemati & Zanjan(48) & $2012-2013$ & 120 & 29.2 & NA & 23.3 \\
\hline 16 & Nakhaei & Mashhad(49) & 2014 & 70 & 35.7 & 11.4 & NA \\
\hline 17 & Rostamour & Shiraz(50) & $2012-2013$ & 42 & 61.9 & NA & 11.9 \\
\hline 18 & Akhavan & Yazd(28) & $2011-212$ & 54 & 29.5 & NA & NA \\
\hline
\end{tabular}

data weighted by the inverse variance of the individual studies were pooled to derive an overall proportion and the associated $95 \% \mathrm{CI}$. Data extraction and definitions: The following data were extracted from each study: name of first author, location of study, time of study, total number of samples, and reported MBL resistance genes prevalence (Table 1). Furthermore, to minimize the potential bias caused by an inadequate sample size, articles with less than 40 subjects and antibiotic resistant table 
were omitted. Inconsistency between the reviewers was resolved through discussion.

\section{Findings}

In this study, a total of 410 articles were found through databases search, of which overall participants of 18 (abstract with full-text articles) eligible studies were included in this meta-analysis to determine the prevalence of MBL producing P. aeruginosa strains (Figure1).

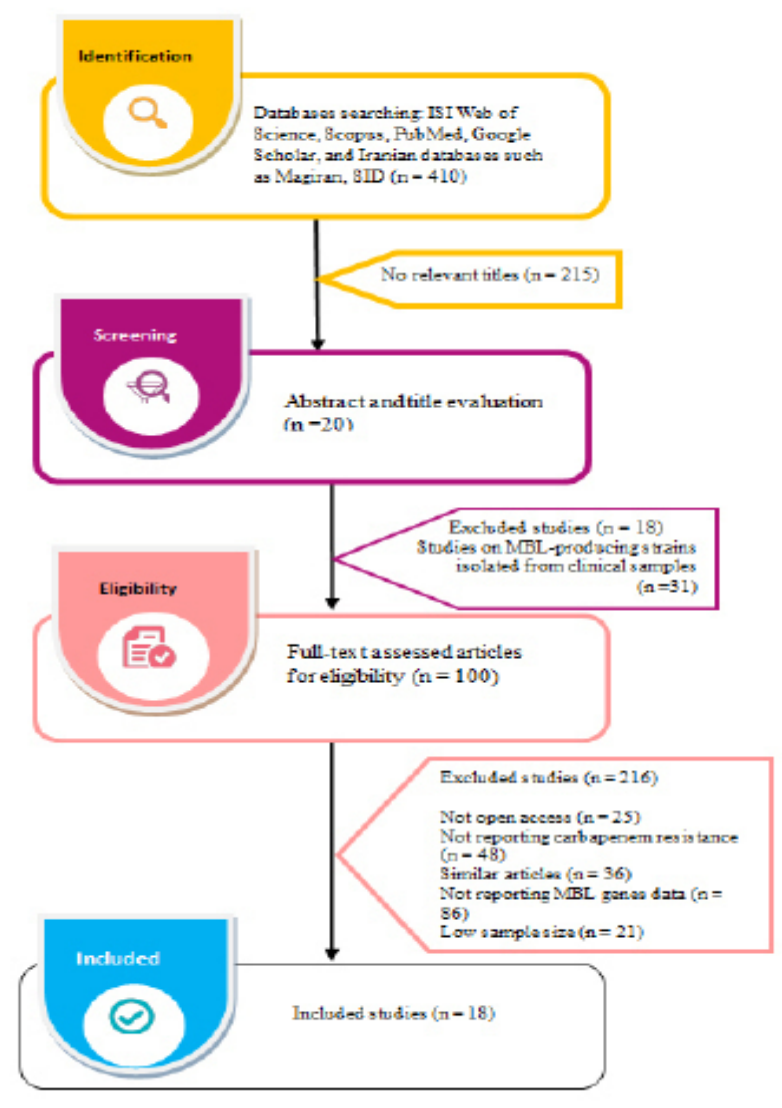

Figure 1) Schematic diagram of the literature search and study selection.

In the present study, the results of some MBL genes (SPM, NDM) were not reported for some reasons, including: negative results and not being included in the reviewed studies. Also, the results of antibiotic resistance were not mentioned in some articles due to lack of reporting. Considering the location of the studies, most of the studies were conducted in Tehran ( $n=6)$, Esfahan $(n=2)$, and Shiraz $(n=2)$ compared to studies conducted in other locations $(\mathrm{n}=8)$.

Based on the present study findings, the prevalence of MBL-producing $P$. aeruginosa strains in Iranian population was about $49 \%$ (95\% CI: 33-65). However, publication bias was not significant. In addition, in Iranian population, the most prevalent MBL genes were $b a_{I M P}$ with $17 \%(95 \% \mathrm{CI})$ and bla $_{V I M}$ with 13\% (95\% CI), respectively (Figure 2, 3).

\section{Discussion}

Today, pathogens such as $P$. aeruginosa strains are considered as the leading cause of nosocomial infections due to the formation of very strong biofilms and the development of various antibiotic resistances in many areas, including Iran ${ }^{[17,19]}$. For this reason, this study was conducted to investigate the prevalence of such resistance mechanisms, including the presence of metallo- $\beta$-lactamase (MBL) resistance genes in this microorganism, in order to point out the importance of this issue and to make constructive suggestions to deal with such cases in not so far future. Thus, the present analysis revealed that the prevalence of MBL-producing $P$. aeruginosa strains in Iranian hospitals in burn units is alarmingly high, with an overall estimated prevalence rate of about 49\% (95\% CI: 33$65)$. According to the analysis, it seems that the prevalence of MBLs genes in Iranian burn infections is very significant.

In various studies, the prevalence of such resistance genes has been further investigated. For example, a study by Lautenbach et al. (2010) revealed a high degree of carbapenem resistance in $P$. aeruginosa strains, and its relationship with mortality was discussed ${ }^{[20]}$. Another study conducted in three German hospitals also noted the importance of such resistance, while the other study by Erlandsson et al. (2008) in Swedish ICUs expressed that the prevalence of MBL production by this microorganism (P. aeruginosa) was about 


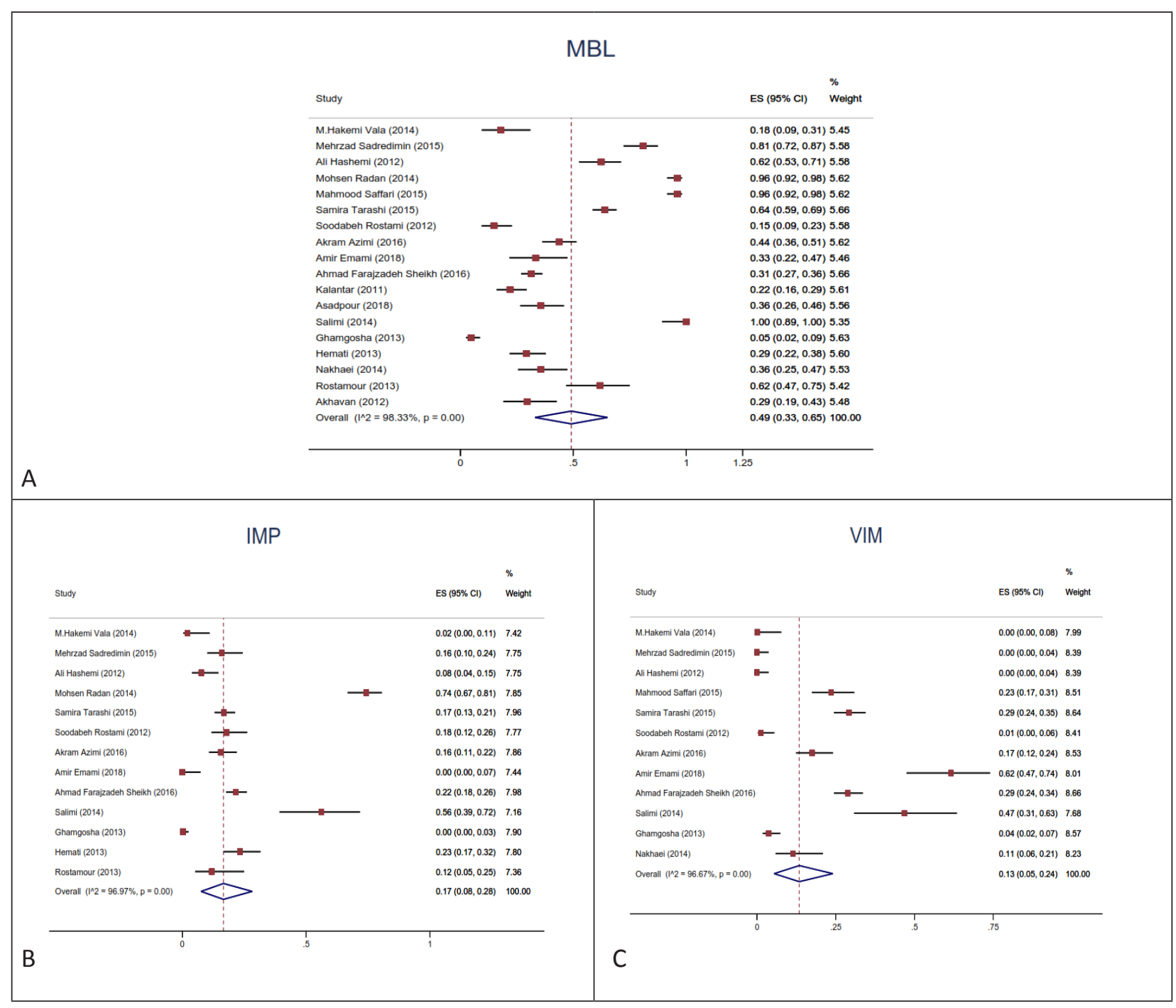

Figure 2) Forest plot of the studies on burn patients (meta-analysis). (A), (B), and(C) represent the prevalence of MBL, IMP, and VIM genes.

less than 1\% ${ }^{[21]}$. Liakopoulos et al. (2013) in Greece revealed that $28 \%$ of investigated isolates were MBL-producer ${ }^{[22]}$. Also, another study conducted in 23 Korean hospitals during 2005 demonstrated that $10.8 \%$ of $P$. aeruginosa isolates could produce MBL ${ }^{[23]}$. Kaleem et al. (2010) in Pakistan revealed that the prevalence of MBL-producing $P$. aeruginosa isolates was about $78 \%$ [24]. Also, Hashem et al. (2017) showed that the prevalence of MBL-producing $P$. aeruginosa was $64 \%$ in Egypt ${ }^{[25]}$. In another study by Ghasemian et al. (2018), some important results were found from different parts of Iran. They reported that $55 \%$ of $P$. aeruginosa isolates were resistant to imipenem and meropenem, among which $37.72 \%$ were MBL producers, and the prevalence rates of bla $_{V I M}$ and $b l a_{I M P}$ in burn isolates were $11.50 \% \pm 3.5 \%$ and $24.65 \% \pm 23$, respectively [26].

In comparison with all the above mentioned results, in the present study, the highest prevalence rate was reported for $b l a_{I M P}$ (17\%) (95\% CI) and bla ${ }_{V I M}(13 \%)(95 \% \mathrm{CI})$, respectively.

Therefore, the analysis in this study shows that genes bla $_{I M P}$ and bla $_{V I M}$ are prevalent among burn patients in Iran. This study results are similar to previous studies results reported by other authors, but in this study we tried to both point out the importance 


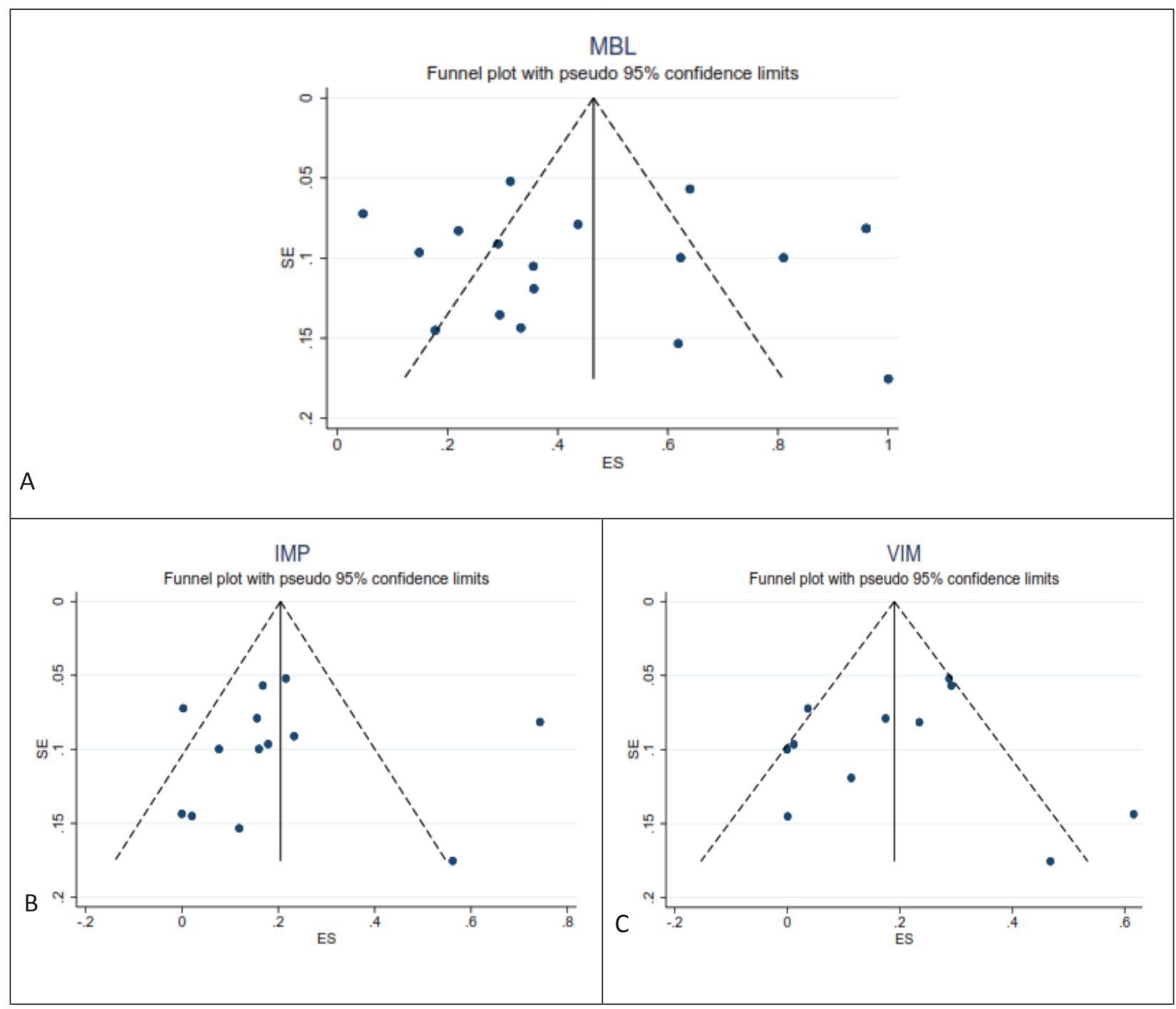

Figure 3) (A) Funnel plot of the studies on burn patients (meta-analysis). (A), (B), and(C) represent the prevalence of MBL, IMP, and VIM genes.

of this issue and suggest a useful and constructive solution to deal with this issue. According to the results of this study, the prevalence of MBL resistance among burn centers in Iran is relatively high compared to industrialized countries such as Sweden and Norway [27]. One of the reasons for this difference is the existence of effective programs in infection control systems to combat various types of nosocomial infections and their more attention to this issue. But in a developing country like Iran, these cases are poorly controlled due to the lack of a coherent and effective program to deal with these cases, and this causes a lot of problems in the treatment of various drug- resistant nosocomial infections [1]. Along with other problems caused by Pseudomonas, we could mention the ability of this bacterium to grow well in the humid hospital environments. Low sensitivity to antibiotics is a prominent feature of this bacterium, which makes treatment difficult. This bacterium is resistant to various antibiotics by different mechanisms. Class $B$ beta-lactamases are metallo- $\beta$-lactamases that require the presence of one or two ions $(\mathrm{Zn})$ in their active site. Metallo- $\beta$-lactamases have the ability to inactivate all beta-lactam antibiotics except monobactam. Multidrugresistant strains are on the rise today due to the overuse of antibiotics ${ }^{[28]}$. 


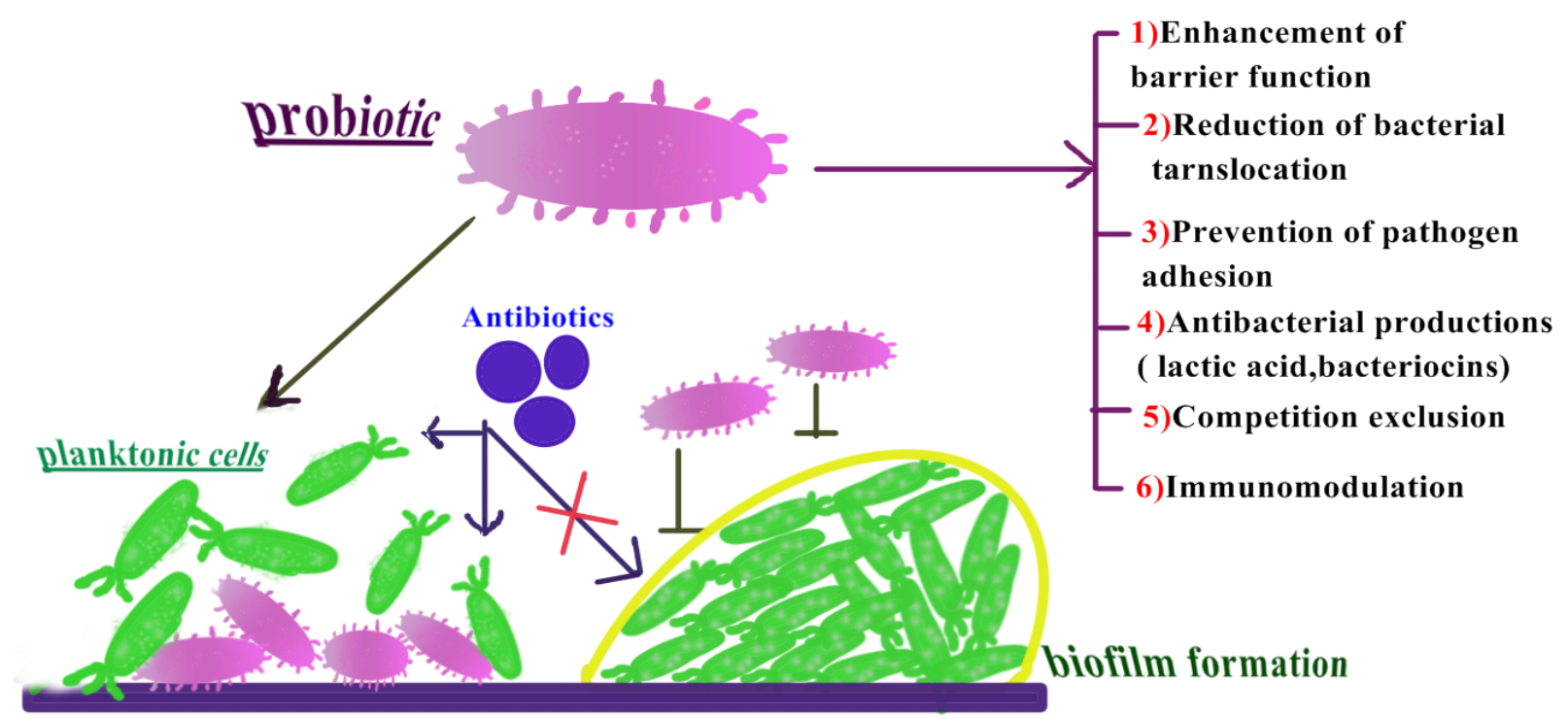

Figure 4) Probiotic activities against pathogens.

Since imipenem is prescribed as a preventative treatment in the burn injury wards to prevent burn wound infection, increased resistance is inevitable, and the common use of carbapenems to prevent Pseudomonas infection in burn units could be effective in preventing its spreading. In burn units, antibiotic susceptibility testing and MBL-producing P. aeruginosa strains should be considered prior to drug administration. Due to the fact that MBL enzymes are of different classes with various prevalence rates in different regions; thus, it is necessary to perform molecular studies in this field ${ }^{[28]}$. As mentioned earlier, one of the most important virulence factors of pathogens such as $P$. aeruginosa is the ability to form biofilms on different biotic and abiotic surfaces. Microorganisms within the biofilms are not only resistant to the host immune system but also to a wide range of antibiotics due to their impenetrable biofilm structure, including extracellular matrix polymer ${ }^{[29-30] .}$ Therefore, in order to deal with resistant strains, special therapeutic strategies are needed. Accordingly, it is suggested to use probiotics as antibacterial and antibiofilm agents producing appropriate products with antagonistic effects against many pathogens, including $P$. aeruginosa, Klebsiella pneumoniae, Salmonella, and other microorganisms [17].

Among the important probiotics used to prevent and eradicate bacterial infections such as resistant $P$. aeruginosa are lactobacilli, the use of cell free supernatant (CFS) containing antibacterial products has recently been considered by many researchers as a new treatment strategy for controlling and preventing the colonization of pathogens, it shows us a clear vision of the future. Lactobacilli could exhibit antibacterial activity through a variety of mechanisms, including: production of inhibitory compounds (such as bacteriocins, biosurfactants, and organic acids), modulation of the host immune system, competition with pathogens for binding to cellular receptors, and nutrient uptake. As a result, they show antagonistic activities against pathogens ${ }^{[17]}$ (Figure 4).

All of these factors indicate how potent this pathogen is in causing infection, and it is a global concern. Therefore, serious solutions must be sought to deal with this important pathogen.

Due to the local conditions, in order to be more effective, it is better to 
carry out infection control schedule recommended by WHO (the World Health Organization). Accordingly, countries with low and medium revenues (such as Iran) could not handle infection control schedules as developed countries in terms of cost and cultural requirements [31-32] In other words, close cooperation of microbiology laboratory with clinicians, quick reporting, the use of some effective treatment strategies, and the use of combination regimens are essential to decrease the spread of antibiotic-resistant P. aeruginosa strains in burn infections [30, 33-34]. Nevertheless, combination regimens should be used very carefully only in patient who has symptom; otherwise, they may cause new resistances [35].

The restrictions of this study should be discussed as follows: (1) the potential influence of sex and age could not be analyzed because the role of age and gender was not studied in most articles. (2) Some articles had to be paid for. (3) Only published articles were considered in the present metaanalysis. Then by comparing the results of this study and several other studies in Iran, attempts were made to provide constructive suggestions to prevent these infections. (4) This study could not entirely indicate the prevalence of MBL-producing P. aeruginosa infections in Iran owing to the fact that imipenem resistance has not yet been investigated in some locations of Iran and also because of the inability to detect such resistances.

Finally, in most burn hospitals in Iran, routine diagnosis of MBL production by $P$. aeruginosa isolates is not performed. Hence, the diagnosis of carbapenem resistance genes is suggested to be included in the agenda of various laboratories in order to properly prescribe appropriate therapeutic antibiotics to combat various nosocomial infections.

\section{Conclusion}

According to the results of this study, the high prevalence of MBL-producing $P$. aeruginosa strains due to lack of timely diagnosis is one of the most important problems in Iranian hospitals. Prevention strategies are needed to reduce the prevalence rate of MBL positive strains in Iran. Basically, standard guidelines are needed to prevent the spread of these strains in hospitals, which are resistant to antibiotics administrated by doctors and healthcare staff. Because prevention is always better than cure. Indiscriminate use of antibiotics, high biofilm formation, and lack of timely diagnosis have resulted in the development of multidrugresistant $P$. aeruginosa infections, which is a serious threat to patients' health. To prevent and eradicate these infections, it is suggested to use probiotics (as beneficial microorganisms by producing various antibacterial products) along with antibiotics in order to speed up the healing process.

Acknowledgments: We would like to thank Dr. Shima Hadifar for her cooperation in editing this article, Mr. Kiarash Tanha for his statistical work, and Maryam Shamkhali.

Ethical permission: None declared by Authors.

Conflicts of interests: None declared by Authors.

Authors' contribution: Conceptualization: LS, MS; Data curation and formal analysis: LS, MS; Investigation: LS, MS; Methodology and project administration: LS, MS; Supervision: LS; Validation: LS, MS; Writing of original draft: LS, MS; Writing, reviewing, and editing: LS, MS.

Fundings: No funding.

Consent to participate: Not applicable.

\section{References}

1. Jabalameli F, Taki E, Emaneini M, Beigverdi R. Prevalence of metallo- 
$\beta$-lactamase-encoding genes among carbapenem-resistant Pseudomonas aeruginosa strains isolated from burn patients in Iran. Revista da Sociedade Bras Med Trop. 2018;51(3):270-6.

2. Faghri J, Nouri S, Jalalifar S, Zalipoor M, Halaji M. Investigation of antimicrobial susceptibility, class I and II integrons among Pseudomonas aeruginosa isolates from hospitalized patients in Isfahan, Iran. BMC Res Notes. 2018;11(1):1-5.

3. Morita Y, Tomida J, Kawamura Y. Responses of Pseudomonas aeruginosa to antimicrobials. Front Microbiol. 2013;4:422.

4. Rostami S, Farajzadeh Sheikh A, Shoja S, Farahani A, Tabatabaiefar MA, Jolodar $A$, et al. Investigating of four main carbapenem-resistance mechanisms in high-level carbapenem resistant Pseudomonas aeruginosa isolated from burn patients. J Chin Med Assoc. 2018;81(2):127-32.

5. El-Domany RA, Emara M, El-Magd MA, Moustafa WH, Abdeltwab NM. Emergence of imipenem-resistant Pseudomonas aeruginosa clinical isolates from Egypt coharboring VIM and IMP carbapenemases. Microb Drug Resist. 2017;23(6):682-6.

6. Khosravi AD, Shafie F, Abbasi Montazeri E, Rostami S. The frequency of genes encoding exotoxin $\mathrm{A}$ and exoenzyme $S$ in Pseudomonas aeruginosa strains isolated from burn patients. Burns. 2016;42(5):1116-20.

7. Khosravi AD, Mihani F. Detection of metallo- $\beta$-lactamase-producing Pseudomonas aeruginosa strains isolated from burn patients in Ahwaz, Iran. Diagn Microbiol Infect Dis. 2008;60(1):125-8.

8. Malkoçoğlu G, Aktaş E, Bayraktar B, Otlu B, Bulut ME. VIM-1, VIM-2, and GES-5 carbapenemases among pseudomonas aeruginosa isolates at a tertiary hospital in Istanbul, Turkey. Microb Drug Resist. 2017;23(3):328-34.

9. Jeon JH, Lee JH, Lee JJ, Park KS, Karim $A M$, Lee CR, et al. Structural basis for carbapenem-hydrolyzing mechanisms of carbapenemases conferring antibiotic resistance. Int J MolSci. 2015;16(5):965492.

10. Hong DJ, Bae IK, Jang IH, Jeong SH, Kang HK, Lee K. Epidemiology and characteristics of metallo-ß-lactamaseproducing Pseudomonas aeruginosa. Infect Chemother. 2015;47(2):81-97.

11. Ramakrishnan K, Rajagopalan S, Nair S, Kenchappa P, Chandrakesan SD. Molecular characterization of metallo $\beta$-lactamase producing multidrug resistant Pseudomonas aeruginosa from various clinical samples. Indian J Pathol Microbiol. 2014;57(4):579-82.

12. Diene SM, Rolain JM. Carbapenemase genes and genetic platforms in Gramnegative bacilli: Enterobacteriaceae, Pseudomonas, and Acinetobacter species. Clin Microbiol Infect. 2014;20(9):831-8.

13. Soares De Macedo JL, Santos JB. Bacterial and fungal colonization of burn wounds. Mem Inst Oswaldo Cruz. 2005;100(5):535-9.

14. Kalantar E, Torabi V, Salimizand H, Soheili F, Ramezanzadeh R. Incidence and susceptibility pattern of metallobeta-lactamase producers among Pseudomonas aeruginosa isolated from burn patients at Kurdistan province. Jundishapur J Microbiol. 2012;5(3):50710.

15. Franklin C, Liolios L, Peleg AY. Phenotypic detection of carbapenem-susceptible metallo- $\beta$-lactamase- producing gramnegative bacilli in the clinical laboratory. J Clin Microbiol. 2006;44(9):3139-44.

16. Gupta V, Datta P, Chander J. Prevalence of metallo- $\beta$ lactamase (MBL) producing Pseudomonas spp. and Acinetobacter 
spp. in a tertiary care hospital in India. J Infect. 2006;52(5):311-4.

17. El-Mokhtar MA, Hassanein KM, Ahmed AS, Gad GFM, Amin MM, Hassanein OFE. Antagonistic activities of cell-free supernatants of lactobacilli against extended-spectrum $\quad \beta$-lactamase producing Klebsiella pneumoniae and Pseudomonas aeruginosa. Infect Drug Resist. 2020;13:543-52.

18. Moghadam SS, Khodaii Z, Zadeh SF, Ghooshchian M,Aghmiyuni ZF, Shabestari TM. Synergistic or antagonistic effects of probiotics and antibiotics-alone or in combination-on antimicrobial-resistant pseudomonas aeruginosa isolated from burn wounds. Arch Clin Infect Dis. 2018;13(3):e63121.

19. Vaez H, Khademi F, Salehi-Abargouei A, Sahebkar A. Metallo-beta-lactamaseproducing pseudomonas aeruginosa in Iran: A systematic review and metaanalysis. Infez Med. 2018;26(3):216-25.

20. Lautenbach E, Synnestvedt M, Weiner MG, Bilker WB, Vo L, Schein J, et al. Imipenem resistance in Pseudomonas aeruginosa emergence, epidemiology, and impact on clinical and economic outcomes. Infect Control Hosp Epidemiol. 2010;31(1):4753.

21. Erlandsson M, Gill H, Nordlinder D, Giske C, Jonas D, Nilsson LE, et al. Antibiotic susceptibility patterns and clones of Pseudomonas aeruginosa in Swedish ICUs. Scand J Infect Dis. 2008;40(67):487-94.

22. Liakopoulos A, Mavroidi A, Katsifas EA, Theodosiou A, Karagouni AD, Miriagou $\mathrm{V}$, et al. Carbapenemase-producing Pseudomonas aeruginosa from central Greece: Molecular epidemiology and genetic analysis of class I integrons. BMC Infect Dis. 2013;13(1):1-7.

23. Yong D, Toleman MA, Giske CG, Cho HS, Sundman K, Lee K, et al. Characterization of a new metallo- $\beta$-lactamase gene, bla NDM-1, and a novel erythromycin esterase gene carried on a unique genetic structure in Klebsiella pneumoniae sequence type 14 from India. Antimicrob Agents Chemother. 2009;53(12):504654.

24. Kaleem F, Usman J, Hassan A, Khan A. Frequency and susceptibility pattern of metallo-beta-lactamase producers in a hospital in Pakistan. J Infect Dev Ctries. 2010;4(12):810-3.

25. Hashem H, Hanora A, Abdalla S, Shaeky A, Saad A. Dissemination of metallo- $\beta$ lactamase in Pseudomonas aeruginosa isolates in Egypt: mutation in blaVIM-4 . Apmis. 2017;125(5):499-505.

26. Ghasemian A, Rizi KS, Vardanjani HR, Nojoomi F. Prevalence of clinically isolated metallo-beta-lactamaseproducing pseudomonas aeruginosa, coding genes, and possible risk factors in Iran. Iran J Pathol. 2018;13(1):1-9.

27. Samuelsen $\emptyset$, Toleman MA, Sundsfjord A, Rydberg J, Leegaard TM, Walder M, et al. Molecular epidemiology of metallo$\beta$-lactamase-producing Pseudomonas aeruginosa isolates from Norway and Sweden shows import of international clones and local clonal expansion. Antimicrob Agents Chemother. 2010;54(1):346-52.

28. Tafti A, Zandi H, Vakli M, Mousavi SM, Zarei M. Frequency of $\beta$-lactamase and metallo- $\beta$-lactamase in Pseudomonas aeruginosa strains isolated from burn wounds in Yazd burn hospital during 2011-2012. Feyz. 2013;18(2):167-74. 29. Ramos-Vivas J, Chapartegui-González I, Fernández-Martínez M, González-Rico C, Fortún J, Escudero R, et al. Biofilm formation by multidrug resistant Enterobacteriaceae strains isolated from solid organ transplant recipients. Sci Rep. 2019;9(1). 
30. Rasamiravaka T, Labtani Q, Duez P, El Jaziri M. The formation of biofilms by pseudomonas aeruginosa: A review of the natural and synthetic compounds interfering with control mechanisms. BioMed Res Int. 2015;2015.

31. Mock C, Peck M, Peden M, Krug E, World Health Organization (WHO). A WHO plan for burn prevention and care. Geneva: World Health Organization; 2008,3.

32. Sadredinamin M, Hashemi A, Goudarzi H, Tarashi S, Yousefi Nojookambari N, Erfanimanesh S. Detection of ISPa1328 and ISPpu21, two novel insertion sequences in the OprD porin and blaIMP-1 gene among metallo-betalactamase-producing Pseudomonas aeruginosa isolated from burn patients. Arch Trauma Res. 2016;6(1):e36239.

33. Weber J, McManus A, Nursing Committee of the International Society for Burn Injuries. Infection control in burn patients. Burn. 2004;30(8):A16-24.

34. Ducel G, Fabry J, Nicolle L. Prevention of hospital acquired infections: A practical guide. 2nd Ed. Geneva: World Health Organization; 2002.

35. Arslan E, Dalay C, Yavuz M, Göcenler L, Acartürk S. Gram-negative bacterial surveillance in diabetic patients. Ann Burns Fire Disasters. 1999;12(2).

36. Hakemi Vala $M$, Hallajzadeh $M$, Hashemi A, Goudarzi H, Tarhani M, Sattarzadeh Tabrizi $M$, et al. Detection of ambler class A, B and D $\beta$-Lactamases among Pseudomonas Aeruginosa and Acinetobacter Baumannii clinical isolates from burn patients. Ann Burns Fire Disasters. 2014;27(1):8-13.

37. Sadredinamin M, Hashemi A, Goudarzi H, Tarashi S, Nojookambari NY, Taki E, et al. Detection of blaIMP, blaVIM and OprD genes among pseudomonas aeruginosa isolated from burn patients. J Mazandaran Univ Med Sci. 2016;26(138):181-6.
38. Hashemi A, Fallah F, Erfanimanesh S, Chirani A, Dadashi M. Detection of antibiotic resistance genes among Pseudomonas aeruginosa strains isolated from burn patients in Iran. $\mathrm{Br}$ Microbiol Res J. 2016;12(4):1-6.

39. Radan M, Moniri R, Khorshidi A, Gilasi $H$, Norouzi Z, Beigi F, et al. Emerging carbapenem-resistant Pseudomonas aeruginosa isolates carrying blaIMP among burn patients in Isfahan, Iran. Arch Trauma Res. 2016;5(3).

40. Saffari M, Firoozeh F, Pourbabaee M, Zibaei M. Evaluation of metallo- $\beta$ lactamase-production and carriage of bla-VIM genes in Pseudomonas aeruginosa isolated from burn wound infections in Isfahan. Arch Trauma Res. 2016;5(4):e34343..

41. Tarashi S, Goudarzi H, Erfanimanesh S, Pormohammad A, Hashemi A. Phenotypic and molecular detection of metallobeta-lactamase genes among imipenem resistant pseudomonas aeruginosa and acinetobacter baumannii strains isolated from patients with burn injuries. Arch Clin Infect Dis. 2016;11(4):e39036.

42. Azimi A, Peymani A, Pour PK. Phenotypic and molecular detection of metallo$\beta$-lactamase-producing Pseudomonas aeruginosa isolates from patients with burns in Tehran, Iran. Rev Soc Bras Med Trop. 2018;51(5):610-5.

43. Emami A, Pirbonyeh N, Keshavarzi A, Bazargani A, Hassanpour S, Javanmardi F. Evaluating the saliva of burn ICU patients for resistant infections harbor metallo- $\beta$-lactamase genes. J Burn Care Res. 2020;41(3):647-51.

44. Farajzadeh Sheikh A, Shahin M, Shokoohizadeh L, Ghanbari F, Solgi $H$, Shahcheraghi F. Emerge of NDM1-producing multidrug-resistant pseudomonas aeruginosa and coharboring of carbapenemase genes 
in South of Iran. Iran J Public Health. 2020;49(5):959-67.

45. Asadpour L. Antimicrobial resistance, biofilm-forming ability, and virulence potential of Pseudomonas aeruginosa isolated from burn patients in northern Iran. J Glob Antimicrob Resist. 2018;13:214-20.

46. Salimi F, Eftekhar F. Prevalence of blaIMP and blaVIM gene carriage in metallo$\beta$-lactamase-producing burn isolates of Pseudomonas aeruginosa in Tehran. Turk J Med Sci. 2014;44(3):511-4.

47. Ghamgosha M, Shahrekizahedani S, Kafilzadeh F, Bameri Z, Taheri RA, Farnoosh G. Metallo-beta-lactamase VIM-1, SPM-1, and IMP-1 genes among clinical Pseudomonas aeruginosa species isolated in Zahedan, Iran. Jundishapur J Microbiol. 2015;8(4):e17489.
48. Hemmati F, Sourouri Zanjani R, Haghi F, Zeighami H. Determination of antibiotic resistance profile and frequency of metallo-beta- lactamases in Pseudomonas aeruginosa isolates. J Zanjan Univ Med Sci Health Services. 2014;22(93):77-85.

49. Nakhaei Moghaddam M. HMH. Detection of metallo-beta-lactamase blaVIM-1 gene in clinical isolates of Pseudomonas Aeruginosa in Mashhad. J Shahid Sadoughi Univ Med Sci. 24(1):74-82. 50. Rostam Pour S, Gorzin A, Motamedi G. Frequency of blaKHM-1, blaIMP-1,2 and blaSPM-1 genes in clinical isolates of metallo $\beta$-lactamase producing Pseudomonas aeruginosa in hospitalized burned patients in Ghotbeddin Shirazi Hospital. J Inflamm Dis. 2015;19(2):21-9. 